\title{
Multiple genetic switches spontaneously modulating bacterial mutability
}

\author{
Fang Chen ${ }^{1,2}$, Wei-Qiao Liu ${ }^{1,3}$, Abraham Eisenstark ${ }^{4}$, Randal N Johnston ${ }^{5}$, Gui-Rong Liu ${ }^{1 *}$, Shu-Lin Liu ${ }^{1,2,3^{*}}$
}

\begin{abstract}
Background: All life forms need both high genetic stability to survive as species and a degree of mutability to evolve for adaptation, but little is known about how the organisms balance the two seemingly conflicting aspects of life: genetic stability and mutability. The DNA mismatch repair (MMR) system is essential for maintaining genetic stability and defects in MMR lead to high mutability. Evolution is driven by genetic novelty, such as point mutation and lateral gene transfer, both of which require genetic mutability. However, normally a functional MMR system would strongly inhibit such genomic changes. Our previous work indicated that MMR gene allele conversion between functional and non-functional states through copy number changes of small tandem repeats could occur spontaneously via slipped-strand mis-pairing during DNA replication and therefore may play a role of genetic switches to modulate the bacterial mutability at the population level. The open question was: when the conversion from functional to defective MMR is prohibited, will bacteria still be able to evolve by accepting laterally transferred DNA or accumulating mutations?

Results: To prohibit allele conversion, we "locked" the MMR genes through nucleotide replacements. We then scored changes in bacterial mutability and found that Salmonella strains with MMR locked at the functional state had significantly decreased mutability. To determine the generalizability of this kind of mutability 'switching' among a wider range of bacteria, we examined the distribution of tandem repeats within MMR genes in over 100 bacterial species and found that multiple genetic switches might exist in these bacteria and may spontaneously modulate bacterial mutability during evolution.
\end{abstract}

Conclusions: MMR allele conversion through repeats-mediated slipped-strand mis-pairing may function as a spontaneous mechanism to switch between high genetic stability and mutability during bacterial evolution.

\section{Background}

A balance between genetic stability and mutability is essential for bacteria to both retain species identities over long evolutionary times and enable adaptability to changing environments, but little is known about the mechanisms for establishing, maintaining and modulating such a balance. It is richly documented that, under usual growth conditions, genetic stability is largely assured by the functional DNA replication and repair systems. Conversely, when the environment becomes stressful, genetic modifications through mutation or

\footnotetext{
* Correspondence: grliu.natsumi@gmail.com; slliu@ucalgary.ca 'Genomics Research Center (one of The State-Province Key Laboratories of Biomedicine-Pharmaceutics of China), Harbin Medical University, Harbin, China

Full list of author information is available at the end of the article
}

acquisition of exogenous DNA may provide novel traits for greater adaptability of organisms.

Among the known systems for maintaining genetic stability, the DNA mismatch repair (MMR) machinery is the most powerful contributor to the inhibition of mutation and recombination events [1-6]. Bacteria that have elevated mutation rates due to defects in MMR genes, e.g., mutS, mutL or $m u t H$, are termed mutators or hypermutators and have been isolated from various human pathogens or commensals [7-11]. The mutator genotype may confer a temporary selective advantage for the bacteria under stressful conditions, as it allows for the creation of genetic novelties, including stochastic mutations and incorporation of a great diversity of exogenous DNAs [12,13]. However, as most mutations or intruding DNAs are likely to be harmful, the continuous existence of defective MMR alleles would eventually lead to loss of
C Biomed Central

C 2010 Chen et al; licensee BioMed Central Ltd. This is an Open Access article distributed under the terms of the Creative Commons Attribution License (http://creativecommons.org/licenses/by/2.0), which permits unrestricted use, distribution, and reproduction in any medium, provided the original work is properly cited. 
fitness. One may therefore predict that bacteria should be able to optimize their evolutionary fitness through mechanisms that balance the MMR system between functional and non-functional states, allowing beneficial changes to be made when needed and otherwise minimizing the accumulation of harmful changes. To date, such mechanisms have not been identified.

In previous work, we demonstrated that conversion of $m u t L$ between functional and defective $(6 \mathrm{bp} \Delta m u t L$, which had a deletion of one of three tandem repeats within the gene sequence, Figure 1) alleles may act as a genetic switch to modulate bacterial mutability at the population level $[14,15]$. Unlike other mechanisms such as the SOS response, the RpoS regulon, DinB errorprone DNA polymerase, RecA, etc., which undoubtedly all can generate a high mutability state and can contribute to bacterial evolution [16-23], the repeats-mediated allele conversion via slipped-strand mis-pairing seems to be the only known mechanism that is spontaneous and can respond to environmental changes swiftly. To validate the existence of such a genetic switch(s) and to determine whether mutation or recombination events can actually take place only when the switch is set at the non-functional state, we experimentally locked MMR into either functional or non-functional states so that spontaneous conversion between the two states would become unlikely and then scored bacterial mutability. We found that, when the switch was locked at the functional state, genomic evolutionary events (mutation and recombination) were significantly inhibited. This genetic switch model may be generalized to other bacteria, as small repeats also exist in their MMR genes and may mediate allele conversion through slippedstrand mis-pairing.

\section{Results}

Detection of conversion between functional and defective mutL alleles

As the special structure of the tandem GCTGGC repeats in $m u t L$ is expected to easily lead to deletion or duplication of a copy of the six bases via slipped-strand mis-pairing and in turn to changes in bacterial mutability $[14,15]$, we first needed to experimentally validate the effects of mutL allele conversions on mutability. For this, we cultured the S. typhimurium LT7 mutator strain 9052D1, which had the 6bp $\Delta m u t L$ genotype [14], and screened for spontaneous allele conversion between $m u t L$ and $6 \mathrm{bp} \Delta m u t L$. When started, the culture contained only (or mostly) $6 \mathrm{bp} \Delta m u t L$ cells. During incubation, the bacterial culture showed a gradual increase in the fraction of wild type mutL cells - on day 30 , the population contained approximately equal numbers of $m u t L$ and $6 \mathrm{bp} \Delta m u t L$ cells (Figure $2 \mathrm{~A}$ ). A spontaneous mutL revertant obtained from $9052 \mathrm{D} 1$ on day 60 was saved and designated 9052D1R for subsequent analysis.

To monitor the allele conversion from $m u t L$ to 6bp $\Delta m u t L$, we constructed a $t y r$ auxotroph in 9052D1R and designated it 9052D1R Tyr-. When inoculated into M9 minimal medium supplemented with gradually decreasing concentrations of tyrosine (nutrients gradually become scarce over time), $6 \mathrm{bp} \Delta m u t L$ cells in 9052D1R Tyr- were detected, slowly increased as a fraction of the population and eventually predominated (Figure 2B). Conversely, we did not find any detectable allele conversion in Salmonella non-mutators such as SGSC1417 and SGSC1412 (Figure 2B). This may be due either to real absence or to very low frequencies of $6 \mathrm{bp} \Delta m u t L$ cells in the bacterial population. We thus increased the screening scale from 100 to over ten

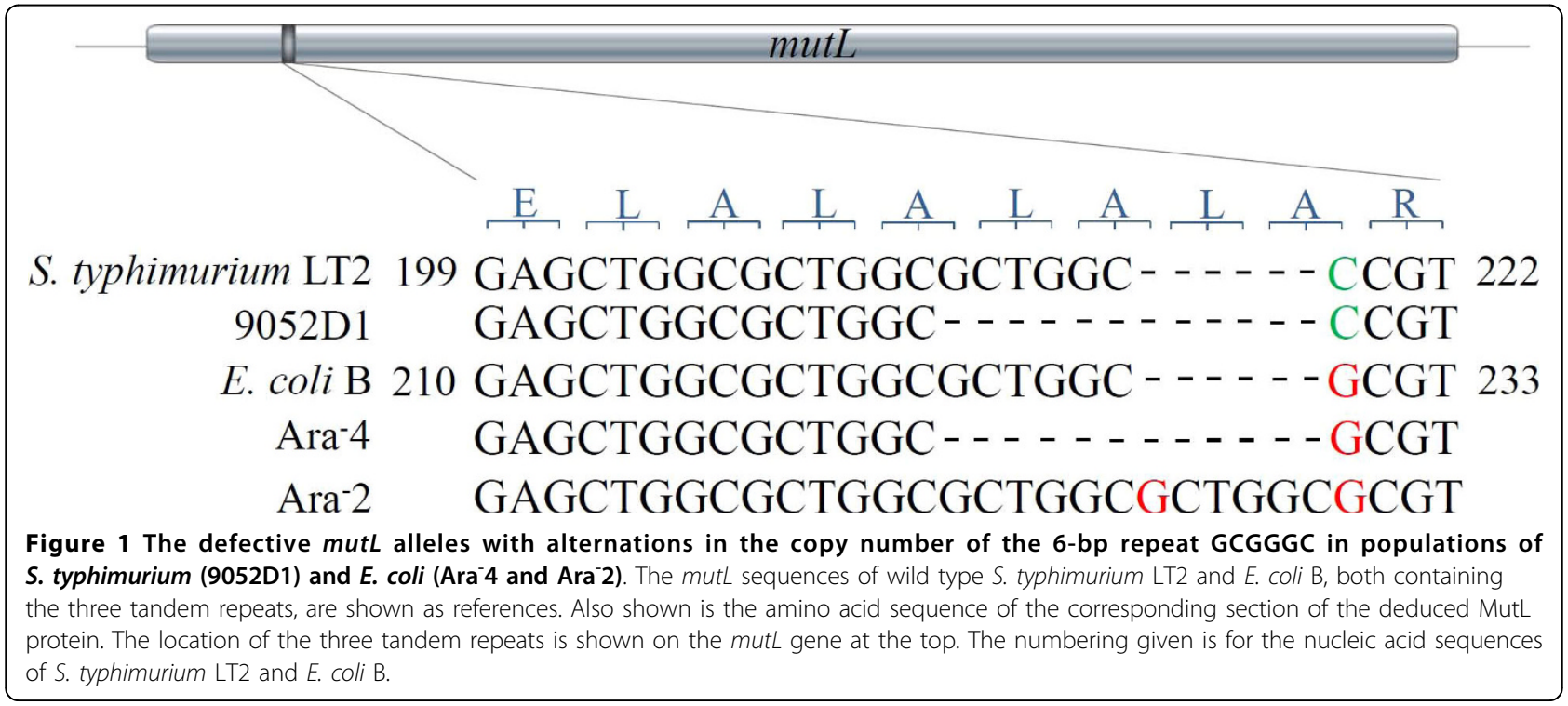




\begin{tabular}{|l} 
A Lane \\
Day
\end{tabular}

thousand single colonies. Nevertheless, no allele conversion was detected either. Detection might become possible had we kept increasing the screening scale, e.g., from thousands to millions of single colonies or more, but such work scales would not be practical by conventional methods. Furthermore, if we did not find the allele conversion even at the million-colony scale, we would still not be able to distinguish between absence and low frequency of $6 \mathrm{bp} \Delta m u t L$ cells in these bacteria and, consequently, could not draw any conclusion regarding whether such a spontaneous genetic switch may exist in these bacterial populations. Therefore, alternative methods had to be sought for a definite answer, such as "locking" the mutL gene to prevent it from conversion between the wild type and $6 \mathrm{bp} \Delta m u t L$ alleles and then inspecting overall mutability changes of the bacterial population.

\section{Construction of strains containing different mutL alleles and evaluation of their mutability}

As the inter-conversion between the wild type mutL and 6bp $\Delta m u t L$ alleles in S. typhimurium LT7 results from copy number changes in the tandem 6 bp repeats (GCTGGC; three copies in wild type mutL and two copies in $6 \mathrm{bp} \Delta m u t L$ ) via slipped-strand mis-pairing $[14,24,25]$, we sought to experimentally prevent the conversion by disrupting the sequence identity between the tandem repeats through base substitution that would not change the amino acids encoded. For example, we "locked" mutL allele into its functional state by converting GCTGGC GCTGGC GCTGGC to GCTTGC CC TGGC GCTGGC (modified bases are underlined), using a gene replacement technique [26]. The modified sequence still encodes the amino acids LALALA, but the three $6 \mathrm{bp}$ sequences are no longer identical and thus slipped-strand mis-pairing should be inhibited. We introduced the "locked" mutL allele (designated $m u t L^{\text {Locked-1 }}$ ) into S. typhimurium LT2 and obtained $\mathrm{LT} 2^{\text {mutL }} \mathrm{L} 1$ (Table 1). Similarly, we "locked" the 6bp $\Delta m u t L$ allele into its non-functional state (designated $6 \mathrm{bp} \Delta m u t L^{\text {Locked; }}$ Table 2) and constructed LT2 ${ }^{6 \mathrm{bp} \Delta m u t L} \mathrm{~L}$ (Table 1). We chose to use S. typhimurium LT2 rather than S. typhimurium LT7 for this experiment due to the consideration that its whole genome sequence is known so that all genetic manipulations could be made with ease. As a control, we constructed strain LT2 ${ }^{\text {mutL L }}$ L1U (Table 1), in which the "locked" mutL allele was "unlocked" through restoration of the original wild type $m u t L$ allele sequence (Table 2). As a control experiment to estimate the impact of synonymous substitutions on bacteria, we arbitrarily changed codon 30 in mutL from CTG to CTT (both encoding amino acid $\mathrm{L}$ ) and obtained $\mathrm{LT} 2^{\text {mut }} \mathrm{LC}$ (Table 1).

Mutation rates of these constructed isogenic strains shown in Figure 3 unambiguously demonstrated the key roles of mutL allele conversion in modulating 
Table 1 Plasmids and strains used in this study

\begin{tabular}{|c|c|c|}
\hline Plasmid or strain & Genotype and/or description & Reference of source \\
\hline pGEM-T easy & A-T cloning vector, $A p^{R}$ & Promega \\
\hline pHSG415 & temperature sensitive, $\mathrm{Cm}^{\mathrm{R}}, \mathrm{Km}^{\mathrm{R}}, \mathrm{Ap}^{\mathrm{R}}$ & Reference: [26] \\
\hline SGSC1417 & S. typhimurium LT7 non-mutator, wild type & Reference: [41] \\
\hline SGSC1412 & S. typhimurium LT2 non-mutator, wild type & Reference: [41] \\
\hline 9052D1 & S. typhimurium LT7 mutator, genome unchanged, $6 \mathrm{bp} \Delta$ mutL & This study \\
\hline 9052D1R & 9052D1, spontaneous mutL revertant & This study \\
\hline$L T 2^{\text {mutL } L 1}$ & SGSC1412, mutL replaced by mutL ${ }^{\text {Locked-1 }}$ & This study \\
\hline $\mathrm{LT} 2^{\text {mutL }} \mathrm{L} 2$ & SGSC1412, mutL replaced by mutL ${ }^{\text {Locked-2 }}$ & This study \\
\hline $\mathrm{LT} 2^{\text {mutL } L 3}$ & SGSC1412, mutL replaced by mutL ${ }^{\text {Locked-3 }}$ & This study \\
\hline $\mathrm{LT} 2^{\text {mutL } L 4}$ & SGSC1412, mutL replaced by mutL ${ }^{\text {Locked-4 }}$ & This study \\
\hline $\mathrm{LT} 2^{\text {mutL }} \mathrm{L} 1 \mathrm{U}$ & SGSC1412L1, mutL ${ }^{\text {Locked-1 }}$ replaced by mutL ${ }^{\text {L1-UL }}$ & This study \\
\hline $\mathrm{LT}^{\text {mutL } L C}$ & SGSC1412, mutL replaced by mutL ${ }^{\text {Locked-C }}$ & This study \\
\hline $\mathrm{LT} 2^{6 \mathrm{bp} \Delta m u t L}$ & SGSC1412, mutL replaced by $6 \mathrm{bp} \Delta$ mutL & This study \\
\hline$L T 2^{6 \mathrm{bp} \Delta m u t L} \mathrm{~L}$ & SGSC 1412 , mutL replaced by $6 \mathrm{bp} \Delta$ mutL ${ }^{\text {Locked }}$ & This study \\
\hline $\mathrm{LT} 2^{\text {muts } \mathrm{L}}$ & SGSC1412, mutS replaced by mutS Locked & This study \\
\hline
\end{tabular}

genetic stability of a bacterial population - when mutL was locked into the functional state (strain $\mathrm{LT} 2^{\text {mutL }} \mathrm{L} 1$ ), the mutability was obviously suppressed compared to its wild type ancestor (LT2), whereas when mutL was locked into its defective state (strain LT2 $2^{6 \mathrm{bp} \Delta m u t L} \mathrm{~L}$ ), the mutability was significantly increased compared to its parent strain $\left(\mathrm{LT} 2^{6 \mathrm{bp} \Delta m u t L}\right)$. Moreover, the mutability of the wild type strain level was seen again when the locked $m u t L$ allele was restored to its convertible wild type sequence. The synonymous base substitution process itself did not lead to apparent influences to the bacterial mutability, as strain LT2 $2^{m u t L} \mathrm{LC}$ exhibited a mutation rate similar to that of wild type LT2 (Figure 3).

We also examined changes in genetic stability by comparing recombination frequencies among these bacterial strains and found the same trend (Figure 4). In conclusion, the prevention of conversion of mutL from the functional to a defective state significantly reduced the capacity of the bacteria to accept genetic novelties that would facilitate their adaptation to environmental pressures, e.g., through mutation to develop antibiotic resistance (Figure 3) or through recombination to acquire needed biosynthesis genes, even when the genes were available in the environment (Figure 4).

\section{Other DNA repeats within mutL and mutS genes in S. typhimurium LT2}

The fact that mutability of a bacterial population comprised of $\mathrm{LT} 2^{m u t L} \mathrm{~L} 1$ was reduced but not completely abolished prompted us to search for other sequence repeats in mutL as well as other MMR genes that might

Table 2 DNA repeats within mutL and mutS genes of S. typhimurium LT2 and synonymous substitution of selected bases

\begin{tabular}{|c|c|c|c|c|c|c|}
\hline Gene & Location & DNA repeats ${ }^{a}$ & Allele & Substituted bases $^{\mathbf{b}}$ & Protein & Description \\
\hline \multirow[t]{6}{*}{ mutl } & $201-218$ & GCTGGCGCTGGCGCTGGCC & mutL $^{\text {Locked-1 }}$ & GCTTGCCCTGGCGCTGGCC & LALALA & $\begin{array}{l}\text { lies in a region that forms a lid over the } \\
\text { ATP-binding pocket of MutL protein }\end{array}$ \\
\hline & & & mutL $^{\mathrm{L} 1-\mathrm{UL}}$ & GCTGGCGCTGGCGCTGGCC & & \\
\hline & 190-195 & $\underline{\text { AAAAAA }}$ & mutL $^{\text {Locked-2 }}$ & $\underline{\mathrm{AAGA} A \mathrm{~A}}$ & KK & $\begin{array}{l}\text { lies in a relatively disordered structure of } \\
\text { ATP-binding pocket of MutL protein }\end{array}$ \\
\hline & $491-496$ & gAAAAAA & mutL ${ }^{\text {Locked-3 }}$ & $\underline{\mathrm{gAG}} \mathrm{AAGA}$ & EK & lies in $\alpha$ helic E of MutL protein \\
\hline & 735-743 & CACCACCACg & mutL ${ }^{\text {Locked-4 }}$ & CACGACTACg & $\pi T$ & $\begin{array}{l}\text { lies in a relatively disordered structure of } \\
\text { MutL C-terminal demonization domain }\end{array}$ \\
\hline & $82-90$ & AAAGAGCTG & mutL ${ }^{\text {Locked-c }}$ & $\underline{\text { AAAGAGCTT }}$ & KEL & lies in the $\alpha$ helic A of MutL protein \\
\hline $6 \mathrm{bp} \Delta$ mutL & $201-212$ & 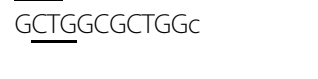 & $6 \mathrm{bp} \Delta m u t L^{\text {Locked }}$ & GCTTGCGCTGGCC & LALA & $\begin{array}{l}\text { lies in a region that forms a lid over the } \\
\text { ATP-binding pocket of MutL protein }\end{array}$ \\
\hline muts & $\begin{array}{l}1189- \\
1195\end{array}$ & $\underline{\text { AAAAAAA }}$ & muts Locked & $\underline{\mathrm{AAG} A A A A}$ & KK & $\begin{array}{l}\text { lies in the C-terminal end of helic } \alpha 16 \text {, } \\
\text { which forms the core domain of the Muts } \\
\text { protein }\end{array}$ \\
\hline
\end{tabular}

a, The first codon encoding the protein is underlined.

b, Italic characters represent modified bases; characters in small case indicate neighboring base of the sequence. 


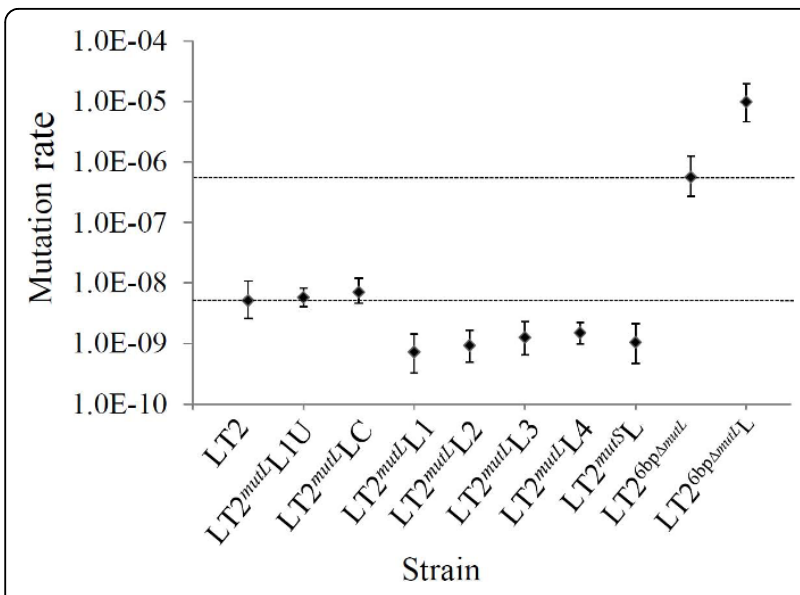

Figure 3 Mutation rates to rifampicin resistance determined by fluctuation tests in isogenic strains carrying different mut $L$ alleles. Error bars indicate 95\% confidence limits. For visual comparison, the dotted horizontal lines illustrate the mutation rates of LT2 (lower line) and LT2 ${ }^{\text {bbp } \Delta m u t L}$ (upper line), respectively.

also play the roles of genetic switches through internal tandem repeat copy number changes. As a result of this more extensive search, we found three additional candidate DNA repeats in mutL and one in mutS in S. typhimurium LT2 (Table 2), all of which could possibly mediate additions or deletions of nucleotides via slipped-strand mis-pairing during replication and thus might influence genetic stability/mutability. To evaluate their potential roles as genetic switches, we constructed a series of isogenic strains, including $\mathrm{LT} 2^{\text {mutL }} \mathrm{L} 2$, $\mathrm{LT} 2^{\text {mutL }} \mathrm{L} 3, \mathrm{LT} 2^{\text {mutL }} \mathrm{L} 4$ and $\mathrm{LT} 2^{\text {mutS }} \mathrm{L}$ (Table 1 ), in which at least one base in the repeats within mutL or

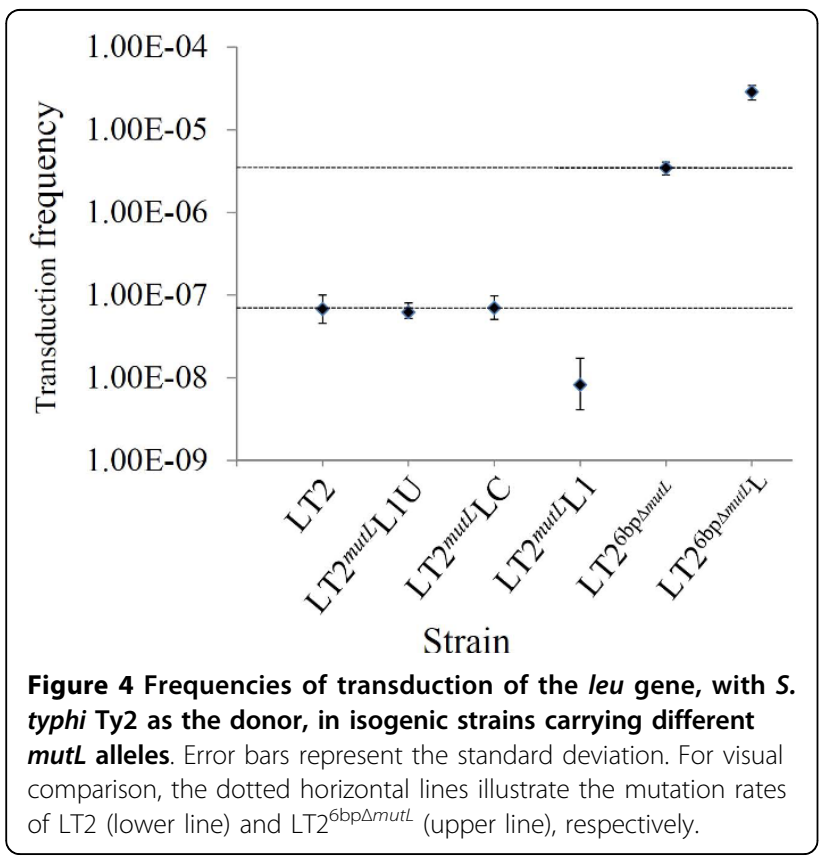

mutS was changed to disrupt the sequence identity among the repeats. As shown in Figure 3, the range of mutability in the bacterial populations decreased 4-7 fold compared to that of the wild type LT2 strain, indicating that these repeats may also serve as switches in modulating the bacterial genetic stability/mutability. We are initiating a series of experiments to lock all of these potential convertible sites in mutL and mutS at the functional states in the same bacterial cell to determine whether the mutability of the bacterial population started with this genetically manipulated cell might be further reduced or even abolished.

DNA repeats within MMR genes in other bacterial species We wondered whether the mutL-6bp $\Delta m u t L$ switch model that we describe in Salmonella might be applicable to other species, as all bacteria should experience a similar need to modulate genetic stability and mutability. After a careful examination of multiple bacterial genomes, we found that the exact $6 \mathrm{bp}$ tandem repeats that are present in the mutL gene of S. typhimurium were identifiable only in bacteria that are very closely related to Salmonella, such as Escherichia and Shigella (Figure 5). In more distantly related bacteria, such as Yersinia or Pseudomonas, there were nucleotide differences in that particular site (Figure 5) that were sufficient to abolish the sequence identity required for allele conversion by slipped-strand mis-pairing. Nevertheless, we found numerous other short DNA repeats (mostly mono- and tri-nucleotide repeats) in other regions of the mutL or mutS genes in over 100 bacterial species (representative examples are shown in Additional file 1: Supplemental Table S1), raising the possibility that genetic switches may be common in a wide range of bacterial species. It is of great interest to notice that in almost all of the common bacterial pathogens several repeats were identified in $m u t L$ and $m u t S$ genes (Additional file 1: Supplemental Table S2). This may enable the pathogenic organisms to counteract host antibacterial responses by allowing rapid evolutionary bursts mediated via transient MMR defects.

\section{Discussion}

The concept of genetic switches for spontaneously modulating mutability is important, as it reconciles the two seemingly conflicting requirements of genetic stability and mutability. Without genetic stability, species continuity would not exist; without mutability, organisms would hardly be able to adapt to changing environments by generating genetic novelty.

The DNA mismatch repair system is well known for its role in maintaining genetic stability [1-3,5,6,12,27-32]. Considerable effort has been devoted to the elucidation of the emergence and molecular causes of MMR defects 


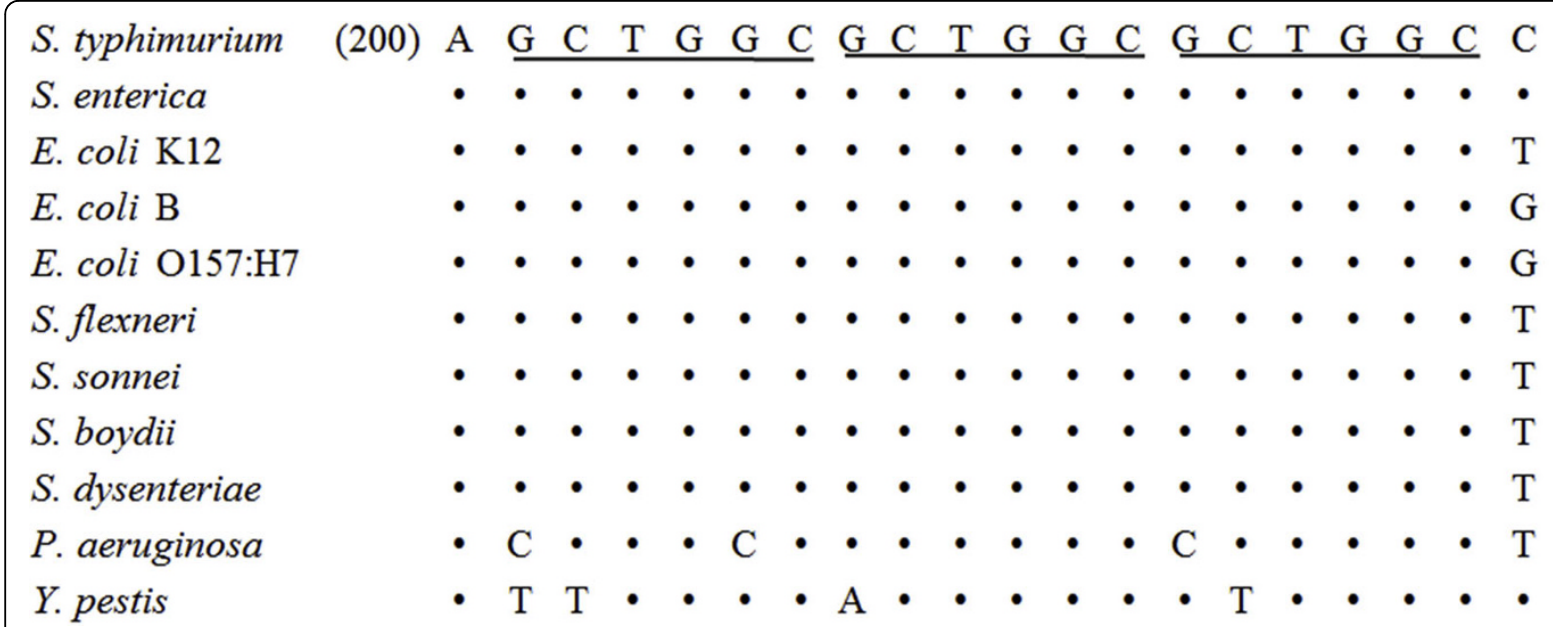

Figure 5 Alignment of the three 6 bp tandem repeats within mutL of S. typhimurium LT2 with homologous sequences of other bacteria. Positions at which the sequences of other bacteria are identical to those of $S$. typhimurium LT2 are indicated by dots. The numbering given in brackets is for the $S$. typhimurium LT2 nucleic acid sequence.

and their impacts on evolution. However, the roles of variable MMR gene function in balancing genetic stability and mutability have received little attention. In this study, we experimentally validated our previous observations about the consequences of mutL/6bp $\Delta m u t L$ allele conversion in bacterial genomic stability and further demonstrated that such conversion might occur in multiple MMR genes, serving as spontaneous genetic switches that bacteria can use to modulate mutability at the population level during evolution.

Some of the results seemed inconsistent with the genetic switch hypothesis. For example, although we readily detected $m u t L$ to $6 \mathrm{bp} \Delta m u t L$ conversion in $S$. typhimurium LT7 mutators, we did not find detectable allele conversion in Salmonella non-mutators (e.g., SGSC1417 and SGSC1412; see Figure 2B), even though our hypothesis would predict the rare appearance of a $6 \mathrm{bp} \Delta m u t L$ genotype under these experimental conditions. However, the "negative findings" do not necessarily mean that the mutL to $6 \mathrm{bp} \Delta m u t L$ conversion was really negative. For instance, if the $6 \mathrm{bp} \Delta m u t L$ frequency was $10^{-8}$ at the start of the experiment and was increased to $10^{-4}$ at the end of the experiment, this ten thousand-fold amplification would still be well beyond the detection capability by the available techniques. We thus attempted to tackle this problem from the opposite direction: if we prevented the $m u t L$ to $6 \mathrm{bp} \Delta m u t L$ conversion when the $6 \mathrm{bp} \Delta m u t L$ genotype was predicted as necessary in a challenging growth environment, would adaptability of the modified bacteria be reduced compared to the wild type controls? When mutL was prevented from conversion to $6 \mathrm{bp} \Delta m u t L$ by nucleotide replacement, we found that bacterial mutability as evidenced by adaptability in challenging environments was significantly reduced. This result demonstrated that conversion from mutL to $6 \mathrm{bp} \Delta m u t L$ plays important roles in bacterial adaptation; success to detect the $6 \mathrm{bp} \Delta m u t L$ at high frequency in some but not all bacterial strains in the experiments may just reflect genetic variations among them, which however will not negate the fact that conversion from $m u t L$ to $6 \mathrm{bp} \Delta m u t L$ may render the bacteria greater adaptability in challenging environments.

We emphasize here that the genetic switch works at the population level. Specifically, we postulate that $6 \mathrm{bp} \Delta m u t L$ cells pre-exist as rare variants in bacterial populations, rather than arising in response to environmental or metabolic challenge. One key point here in the postulation is that they do exist, no matter how low their frequencies might be. Under normal conditions, $6 \mathrm{bp} \Delta m u t L$ cells would not impose any harmful effects because of their low frequencies. Once under stress, bacteria may require novel biological traits to adapt and survive. By chance, some rare $6 \mathrm{bp} \Delta m u t L$ cells in the population may have accumulated "beneficial" nucleotide changes or acquired "useful" exogenous genes and thus will be selected to propagate to increasing subpopulation sizes, eventually predominating in the population. We envision that, following successful adaptation, the $6 \mathrm{bp} \Delta m u t L$ cells would provide no further benefits or may even facilitate deleterious genomic changes and would consequently become once again rare in the bacterial populations. In this way, the mutL-6bp $\Delta m u t L$ switch may establish and maintain a dynamic balance between genetic stability and mutability under different environmental conditions.

Previous work with evolving E. coli populations has also demonstrated spontaneously arising $m u t L$ mutators 
as the result of changes in repeat length [33]. The reported repeat unit in that case was the 6-bp string, CTGGCG, beginning at position 213 of the mutL gene in $E$. coli B. However, we believe that the variable tandem repeat unit should be identified as GCTGGC, starting at position 212 of the $m u t L$ gene in E. coli and also having three repeats in functional mutL, exactly as what we have found in S. typhimurium. Although E. coli B has the two overlapping sets of tandem repeats, we note that three copies of GCTGGC, rather than those of CTGGCG, are conserved throughout the SalmonellaE. coli-Shigella complex (Figure 5) and thus are more likely to function as a common mechanism for modulating genetic stability/mutability in these bacteria.

Although in this study we primarily focused on the $m u t L-6 \mathrm{bp} \Delta m u t L$ switch, our bioinformatic analysis also predicted four other sets of DNA repeats in MMR genes of S. typhimurium LT2, with three in mutL and one in $m u t S$. Because locking these repeats into their functional states also yielded a significant decrease in mutability in the bacterial populations (Figure 3), we suggest that these repeats may also function as genetic switches. It is likely that these multiple mutL or mutS switches work stochastically to spontaneously modulate genetic stability/mutability in bacterial populations, although it is possible that some of the switches might be more functionally important than others according to the ease with which conversion between functional and defective alleles occurs and the effect of the defect on the protein encoded by the MMR gene [15].

Based on the findings reported in this study, we have updated the adopt-adapt model of bacterial evolution $[34,35]$ by assigning a key role for repeats-mediated allele conversion of MMR genes (Figure 6). We suggest first that foreign DNA (acquired by transduction, conjugation or transformation) will be most readily incorporated into the genome of the recipient cell when MMR function is diminished. Second, if the incoming DNA segment is large (100 kb or greater), its incorporation at some site within the genome would cause the normally balanced ori $C$ to $\operatorname{ter} C$ distances to become unequal in the two replicores. As bacteria with unbalanced genomes are less fit and show increased generation times [36], the bacteria that have incorporated the additional DNA ('adopt') may undergo further genomic rearrangements ('adapt') mediated by recombination among partially homologous sequences and facilitated by defective MMR activity to restore oriC to $\operatorname{ter} C$ balance. We further speculate that bacterial speciation events, such as the recent divergence between Salmonella choleraesuis and S. paratyphi C [37], may arise in part through the rapid accumulation of nonsynonymous mutations that are also attributable to variable genetic mutability switches (though not necessarily the $m u t L-6 \mathrm{bp} \Delta m u t L$ switch).
It is worth noting that over-representation of small DNA repeats have also been identified in other stress response genes and virulence genes in bacteria [38-40], but none has so far been directly implicated in a switchlike role for mutability-modulation during bacterial adaptation to environmental challenges. The concept of spontaneous genetic switches based on repeats-mediated allele conversion may therefore be a useful starting point for further investigation of regulatory mechanisms for bacterial adaptive behavior and evolution.

\section{Conclusions}

MMR allele conversion through repeats-mediated slipped-strand mis-pairing could work as a mechanism for spontaneous switching between states of high genetic stability and mutability during bacterial evolution.

\section{Methods}

\section{Bacterial strains, plasmids and media}

Laboratory strains and plasmids used in this study are listed in Table 1. S. typhimurium LT7 mutant 9052D1 was the first strain to have the MMR genes sequenced and was found to have the $6 \mathrm{bp} \Delta m u t L$ genotype [14]. S. typhimurium LT7 non-mutator and S. typhimurium LT2 were originally isolated by Lilleengen [41] in the 1940s as representative strains of phage types LT1 through LT22. Bacterial strains were routinely grown in Luria Bertani (LB) broth as liquid media or on agar plates at $37^{\circ} \mathrm{C}$.

\section{Experimental selection systems for allele conversion}

S. typhimurium LT7 mutator 9052D1 was propagated at $37^{\circ} \mathrm{C}$ by 100 -fold dilutions every 12 hours into $5 \mathrm{ml}$ of fresh LB broth for 60 days ( 1,000 generations). Samples from each population were frozen on days $0,2,4,6,8$, $10,15,20,25,30,45$, and 60 to monitor the spontaneous allele conversion from $6 \mathrm{bp} \Delta m u t L$ to $m u t L$. Spontaneous mutL revertants obtained from the above experiments were designated as 9052D1R. Auxotrophic mutants of 9052D1R, SGSC1417 and SGSC1412 were constructed by $\operatorname{Tn} 10$ insertion inactivation in biosynthetic genes, e.g., in $\operatorname{tyr} A$, as described previously [14]. The auxotrophs, designated as 9052D1R Tyr-, SGSC1417 Tyr- and SGSC1412 Tyr-, respectively, were grown at $37^{\circ} \mathrm{C}$ by 100 -fold dilutions every 12 hours into $5 \mathrm{ml}$ of fresh M9 minimal medium supplemented with gradually decreasing concentrations of tyrosine from $100 \mu \mathrm{g} / \mathrm{ml}$ to $0 \mu \mathrm{g} /$ $\mathrm{ml}$. Trace amounts of the nutrient were used to sustain bacterial growth for some time in order for mutations to accumulate to circumvent the genetic defect in amino acid synthesis. Samples from each population were frozen on days $0,2,4,6,8,10,15,20,25,30,45$, and 60 to monitor the spontaneous allele conversion from mut $L$ to $6 \mathrm{bp} \Delta m u t L$. 


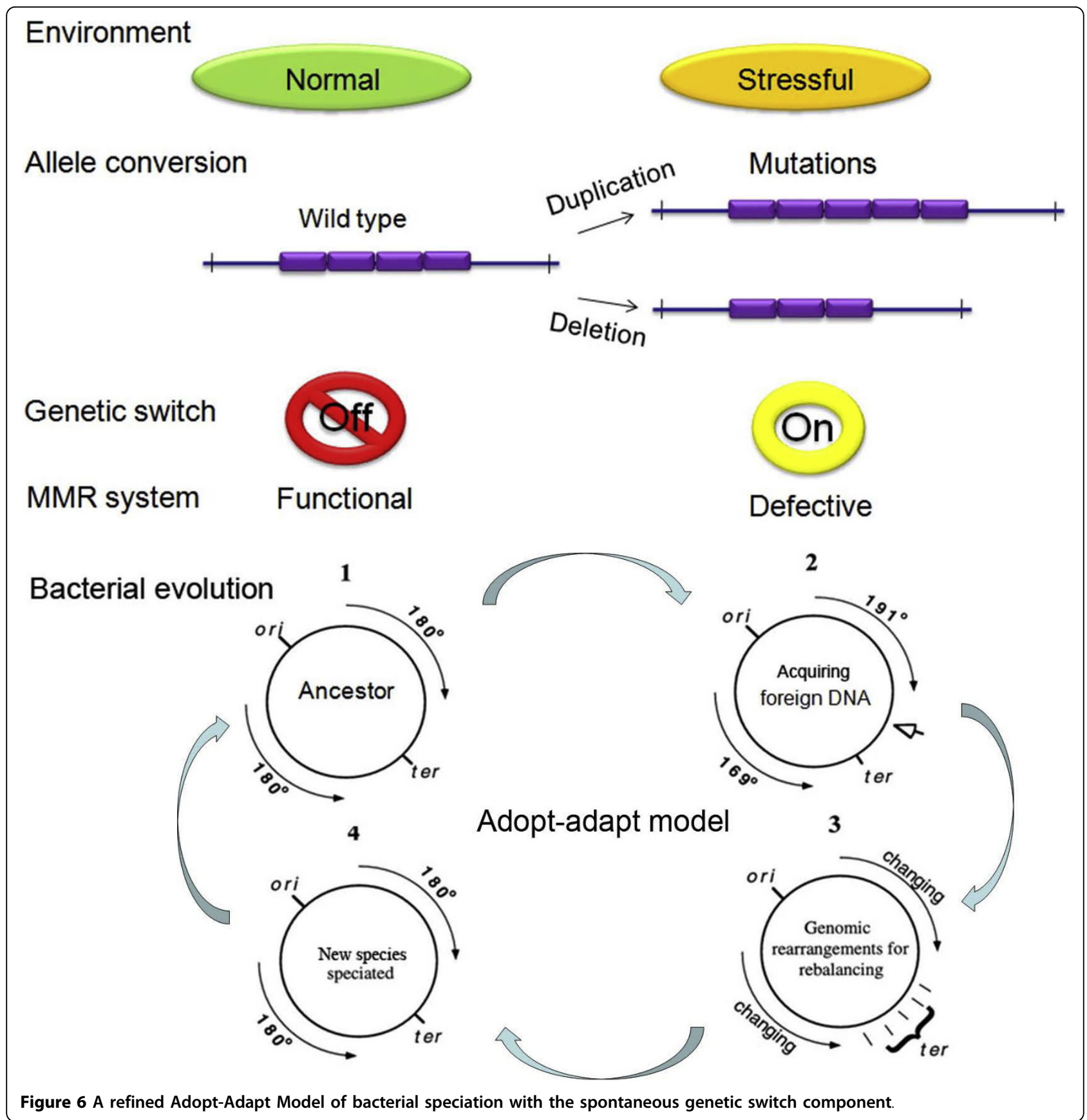

\section{Detection of mutL and $6 \mathrm{bp} \Delta$ mutL alleles}

Polymerase chain reaction (PCR) was used for detection of bacterial cells carrying the mutL or $6 \mathrm{bp} \Delta m u t L$ allele, with the primers L-F1 and L-R1 listed in Additional file 1: Supplemental Table S3. The PCR products, a 130-bp fragment on $6 \mathrm{bp} \Delta m u t L$ and a 136-bp fragment on $m u t L$, were resolved by agarose gel electrophoresis with $5 \%$ agarose (Amersco SFRTM), at $5 \mathrm{~V} / \mathrm{cm}$, for $3 \mathrm{~h}$. The gel was photographed with the Bio-Rad Gel Doc system (Bio-Rad) following electrophoresis.

\section{Gene locking and unlocking}

Synonymous substitutions were introduced into the DNA repeats in mutL or mutS by PCR-based site-directed mutagenesis to construct the locked or unlocked alleles (Table 2), with primers listed in Additional file 1: Supplemental Table S3. The genomic sequence of Salmonella typhimurium LT2 was used as templates for the design of primers. Overlap extension PCR was carried out in two stages. The first stage consisted of a set of two PCR reactions: one from an upstream flanking 
primer (F1) to the negative-sense mutagenesis primer (R1) and the other from a downstream flanking primer (F2) to the positive-sense mutagenesis primer (R2). In the second stage, PCR products from the first stage were used as the templates for a PCR reaction using only the flanking primers (F1, R2). PCR products were purified from agarose gels using AxyPrep DNA gel extraction kits (Axygen) and an A-tailing nucleotide was added with Taq DNA polymerase (Promega) prior to cloning into pGEM T-easy vector (Promega) and transformation of chemically prepared competent $E$. coli DH5 $\alpha$ cells. Transformants were selected on LB agar plates with $100 \mu \mathrm{g} / \mathrm{ml}$ ampicillin. Genes cloned in the resulting plasmids were sequenced by Shanghai Sangon Biological Engineering Technology \& Services Co., Ltd. for both strands.

\section{Gene replacement}

mutL or mutS sequences were obtained from BamHI and EcoRI-digested pGEM-T easy plasmids containing locked or unlocked alleles and subcloned into BamHI and EcoRI-digested pHSG415, a temperature-sensitive vector used for allele replacement via homologous recombination [26]. The recombinant pHSG415 plasmids (pHSG415 containing locked or unlocked alleles) were first transformed into chemically prepared competent E. coli $\mathrm{DH} \alpha$ cells, and then purified and transformed via electroporation (Bio-Rad) into LT2 strains. The allelic exchange experiments were carried out as described by White [26]. Briefly, bacterial strains containing the recombinant plasmids were grown at $42^{\circ} \mathrm{C}$ by 100 -fold dilutions into $5 \mathrm{ml} \mathrm{LB}$ broth with $100 \mu \mathrm{g} / \mathrm{ml}$ ampicillin (LB/Amp broth) daily for 4 days. Dilutions of the final cultures were plated on LB/Amp plates and grown overnight at $42^{\circ} \mathrm{C}$ to select Amp-resistant colonies; 5-8 cointegrate colonies thus obtained were grown at $28^{\circ} \mathrm{C}$ by 100 -fold dilutions into $5 \mathrm{ml} \mathrm{LB}$ broth daily for 4 days. Dilutions of the final cultures were plated on $\mathrm{LB}$ plates and incubated overnight at $28^{\circ} \mathrm{C}$ and then replica-plated onto $\mathrm{LB}$ and $\mathrm{LB} / \mathrm{Amp}$ plates to select Amp-sensitive colonies. Strains with successful allelereplacement were confirmed by sequencing.

\section{Mutation rate measurements}

Fluctuation tests $[42,43]$ were conducted to determine the mutation rates of Salmonella strains carrying different mutL alleles. At least 30 cultures of a given strain were grown from inocula of approximately 1,000 cells for each fluctuation test. Cultures were grown to stationary phase before selective plating on LB agar plates containing $100 \mu \mathrm{g} / \mathrm{ml}$ rifampicin (Rif). Final population sizes were estimated by growing and sampling three extra cultures taken at random for each strain and measuring the total number of colony forming units (CFU) in LB plates without rifampicin. The mutation rate determinations and the statistical analysis from the fluctuation assays were carried out using the MSS Maximum-Likelihood Method as described previously $[43,44]$.

\section{Recombination frequencies estimated by transduction}

Bacteriophage P22-mediated transduction was used to inactivate leu, metC or proB in S. typhimurium LT2 or its isogenic strains by transferring Tn10 insertions as previously described $[45,46]$. For each transduction, 100 $\mu \mathrm{l}$ of recipient cells grown to $5 \times 10^{8} \mathrm{CFU} / \mathrm{ml}$ were infected with $10 \mu \mathrm{l}$ of phage lysate diluted to yield a phage:bacteria ratio of 1:10. Bacterial cultures and phage lysates were mixed directly on M9 minimal medium plates containing glucose $(8 \mathrm{mg} / \mathrm{ml})$ and incubated at $37^{\circ} \mathrm{C}$ for $18 \mathrm{~h}$. The transduction frequency was calculated by determining the number of cells growing on M9 plates divided by the total number of colonies on the LB plates. All experiments were performed in triplicate, and the mean value was recorded.

\section{Bioinformatics analysis of DNA repeats in mutL and mutS genes}

The complete bacterial genome sequences were downloaded from Entrez Genomes (http://www.ncbi.nlm.nih. gov). We screened DNA repeats with motifs of 1-6 nt in length within mutL and mutS genes in over 100 bacterial species. To reduce bias resulting from some genera being represented by multiple species, we counted only one species per genus in each collection. The definition of DNA repeats is: for mononucleotide runs, $\geq 6 \mathrm{nt}$ (six motifs); for dinucleotide runs, $\geq 10$ nt (five motifs); for trinucleotide runs, $\geq 9$ nt (three motifs); for tetranucleotide runs, $\geq 12 \mathrm{nt}$ (three motifs); for pentanucleotide runs, $\geq 15$ nt (three motifs); and for hexanucleotide runs, $\geq 18$ nt (three motifs).

\section{Funding}

This work was supported by a Canadian Institutes of Health Research grant to RNJ; a grant of National Natural Science Foundation of China (NSFC30970078) and a grant of Natural Science Foundation of Heilongjiang Province of China to GRL; a grant from Harbin Medical University, a 985 Project grant of Peking University Health Science Center, grants of National Natural Science Foundation of China (NSFC30870098, 30970119, 81030029) and Specialized Research Fund for the Doctoral Program of Higher Education (SRFDP, 20092307110001) to SLL. 


\section{Additional material}

Additional file 1: Supplemental Materials. The file contains three supplemental tables, i.e., Supplemental Table S1, 2 and 3.

\begin{abstract}
Author details
${ }^{1}$ Genomics Research Center (one of The State-Province Key Laboratories of Biomedicine-Pharmaceutics of China), Harbin Medical University, Harbin China. ${ }^{2}$ Department of Microbiology, Peking University Health Science Center, Beijing, China. ${ }^{3}$ Department of Microbiology and Infectious Diseases, University of Calgary, Calgary, Canada. ${ }^{4}$ Cancer Research Center and University of Missouri, Columbia, Missouri, USA. ${ }^{5}$ Department of Biochemistry and Molecular Biology, University of Calgary, Calgary, Canada.
\end{abstract}

\section{Authors' contributions}

FC carried out the experiments and wrote the first draft of the manuscript. WQL discovered the 6 bp deletion in mutL of LT7 mutator. GRL initiated the mutL project with physical mapping. AE provided the LT7 bacterial strains and mutants. RNJ contributed reagents and helped with editing the manuscript. SLL raised the original research question, designed the project, supervised the experimental work and analyses, and wrote the final version of the manuscript. All authors read and approved the final manuscript.

Received: 9 February 2010 Accepted: 13 September 2010 Published: 13 September 2010

\section{References}

1. Rayssiguier $\mathrm{C}$, Thaler DS, Radman M: The barrier to recombination between Escherichia coli and Salmonella typhimurium is disrupted in mismatch-repair mutants. Nature 1989, 342(6248):396-401.

2. Miller JH: Mutators in Escherichia coli. Mutat Res 1998, 409(3):99-106.

3. Harfe $\mathrm{BD}$, Jinks-Robertson S: DNA mismatch repair and genetic instability. Annu Rev Genet 2000, 34:359-399.

4. Schofield MJ, Hsieh P: DNA mismatch repair: molecular mechanisms and biological function. Annu Rev Microbiol 2003, 57:579-608.

5. Kunkel TA, Erie DA: DNA mismatch repair. Annu Rev Biochem 2005, 74:681-710.

6. Li GM: Mechanisms and functions of DNA mismatch repair. Cell Res 2008, 18(1):85-98.

7. LeClerc JE, Li B, Payne WL, Cebula TA: High mutation frequencies among Escherichia coli and Salmonella pathogens. Science 1996, 274(5290):1208-1211.

8. Sniegowski PD, Gerrish PJ, Lenski RE: Evolution of high mutation rates in experimental populations of E. coli. Nature 1997, 387(6634):703-705.

9. Oliver A, Canton R, Campo P, Baquero F, Blazquez J: High frequency of hypermutable Pseudomonas aeruginosa in cystic fibrosis lung infection. Science 2000, 288(5469):1251-1254.

10. Denamur E, Bonacorsi S, Giraud A, Duriez P, Hilali F, Amorin C, Bingen E, Andremont A, Picard B, Taddei F, Matic I: High frequency of mutator strains among human uropathogenic Escherichia coli isolates. J Bacteriol 2002, 184(2):605-609.

11. Richardson AR, Yu Z, Popovic T, Stojiljkovic I: Mutator clones of Neisseria meningitidis in epidemic serogroup A disease. Proc Natl Acad Sci USA 2002, 99(9):6103-6107.

12. Matic I, Rayssiguier C, Radman M: Interspecies gene exchange in bacteria: the role of SOS and mismatch repair systems in evolution of species. Cell 1995, 80(3):507-515.

13. Taddei F, Radman M, Maynard-Smith J, Toupance B, Gouyon PH, Godelle B: Role of mutator alleles in adaptive evolution. Nature 1997, 387(6634):700-702.

14. Gong J, Liu WQ, Liu GR, Chen F, Li JQ, Xu GM, Wang L, Johnston RN, Eisenstark A, Liu SL: Spontaneous conversion between mutL and 6bpDeltamutL in Salmonella typhimurium LT7: association with genome diversification and possible roles in bacterial adaptation. Genomics 2007, 90:542-549.

15. Chen F, Liu WQ, Liu ZH, Zou QH, Wang Y, Li YG, Zhou J, Eisenstark A, Johnston RN, Liu GR, Liu SL: mutL as a genetic switch of bacterial mutability: turned on or off through repeat copy number changes. FEMS Micorbiol Lett 2010

16. Bjedov I, Tenaillon O, Gerard B, Souza V, Denamur E, Radman M, Taddei F, Matic I: Stress-induced mutagenesis in bacteria. Science 2003, 300(5624):1404-1409.

17. Friedman N, Vardi S, Ronen M, Alon U, Stavans J: Precise temporal modulation in the response of the SOS DNA repair network in individual bacteria. PLOS Biol 2005, 3(7):e238.

18. Ponder $R G$, Fonville NC, Rosenberg SM: A switch from high-fidelity to error-prone DNA double-strand break repair underlies stress-induced mutation. Mol Cell 2005, 19(6):791-804.

19. Finkel SE: Long-term survival during stationary phase: evolution and the GASP phenotype. Nat Rev Microbiol 2006, 4(2):113-120.

20. Galhardo RS, Hastings PJ, Rosenberg SM: Mutation as a stress response and the regulation of evolvability. Crit Rev Biochem Mol Biol 2007, 42(5):399-435.

21. Galhardo RS, Do R, Yamada M, Friedberg EC, Hastings PJ, Nohmi T, Rosenberg SM: DinB upregulation is the sole role of the SOS response in stress-induced mutagenesis in Escherichia coli. Genetics 2009, 182(1):55-68

22. Sundin GW, Weigand MR: The microbiology of mutability. FEMS Microbiol Lett 2007, 277(1):11-20

23. Weigand MR, Sundin GW: Long-term effects of inducible mutagenic DNA repair on relative fitness and phenotypic diversification in Pseudomonas cichorii 302959. Genetics 2009, 181(1):199-208.

24. Streisinger G, Okada Y, Emrich J, Newton J, Tsugita A, Terzaghi E, Inouye M: Frameshift mutations and the genetic code. This paper is dedicated to Professor Theodosius Dobzhansky on the occasion of his 66th birthday. Cold Spring Harb Symp Quant Biol 1966, 31:77-84.

25. Levinson G, Gutman GA: Slipped-strand mispairing: a major mechanism for DNA sequence evolution. Mol Biol Evol 1987, 4(3):203-221.

26. White AP, Collinson SK, Burian J, Clouthier SC, Banser PA, Kay WW: High efficiency gene replacement in Salmonella enteritidis: chimeric fimbrins containing a T-cell epitope from Leishmania major. Vaccine 1999, 17(17):2150-2161.

27. Pang PP, Lundberg AS, Walker GC: Identification and characterization of the mutL and mutS gene products of Salmonella typhimurium LT2. J Bacteriol 1985, 163(3):1007-1015.

28. Modrich P: Mechanisms and biological effects of mismatch repair. Annu Rev Genet 1991, 25:229-253.

29. Yamaguchi M, Dao V, Modrich P: MutS and MutL activate DNA helicase II in a mismatch-dependent manner. J Biol Chem 1998, 273(15):9197-9201.

30. Yang W, Junop MS, Ban C, Obmolova G, Hsieh P: DNA mismatch repair from structure to mechanism. Cold Spring Harb Symp Quant Biol 2000, 65:225-232.

31. Giraud A, Matic I, Tenaillon O, Clara A, Radman M, Fons M, Taddei F: Costs and benefits of high mutation rates: adaptive evolution of bacteria in the mouse gut. Science 2001, 291(5513):2606-2608.

32. Shaver AC, Dombrowski PG, Sweeney JY, Treis T, Zappala RM, Sniegowski PD: Fitness evolution and the rise of mutator alleles in experimental Escherichia coli populations. Genetics 2002, 162(2):557-566.

33. Shaver AC, Sniegowski PD: Spontaneously arising mutL mutators in evolving Escherichia coli populations are the result of changes in repeat length. J Bacterio/ 2003, 185(20):6076-6082.

34. Liu SL, Sanderson KE: Rearrangements in the genome of the bacterium Salmonella typhi. Proc Natl Acad Sci USA 1995, 92(4):1018-1022

35. Liu GR, Rahn A, Liu WQ, Sanderson KE, Johnston RN, Liu SL: The evolving genome of Salmonella enterica serovar Pullorum. J Bacteriol 2002, 184(10):2626-2633.

36. Liu GR, Liu WQ, Johnston RN, Sanderson KE, Li SX, Liu SL: Genome plasticity and ori-ter rebalancing in Salmonella typhi. Molecular Biology and Evolution 2006, 23(2):365-371

37. Liu WQ, Feng $Y$, Wang $Y$, Zou QH, Chen F, Guo JT, Peng $Y H$, Jin $Y$, Li YG, Hu SN, Johnston RN, Liu GR, Liu SL: Salmonella paratyphi C: genetic divergence from Salmonella choleraesuis and pathogenic convergence with Salmonella typhi. PLOS ONE 2009, 4(2):e4510.

38. Hood DW, Deadman ME, Jennings MP, Bisercic M, Fleischmann RD, Venter JC, Moxon ER: DNA repeats identify novel virulence genes in Haemophilus influenzae. Proc Natl Acad Sci USA 1996, 93(20):11121-11125. 
39. van Belkum A, Scherer S, van Alphen L, Verbrugh H: Short-sequence DNA repeats in prokaryotic genomes. Microbiol Mol Biol Rev 1998, 62(2):275-293.

40. Rocha EP, Matic I, Taddei F: Over-representation of repeats in stress response genes: a strategy to increase versatility under stressful conditions? Nucleic Acids Res 2002, 30(9):1886-1894.

41. Lilleengen K: Typing Salmonella by means of bacteriophage. Acta Pathol Microbiol Scand 1948, 77:11-125.

42. Luria SE, Delbruck M: Mutations of Bacteria from Virus Sensitivity to Virus Resistance. Genetics 1943, 28(6):491-511.

43. Rosche WA, Foster PL: Determining mutation rates in bacterial populations. Methods 2000, 20(1):4-17.

44. Foster PL: Methods for determining spontaneous mutation rates. Methods Enzymol 2006, 409:195-213.

45. Liu SL, Hessel A, Sanderson KE: The Xbal-BInl-Ceul genomic cleavage map of Salmonella enteritidis shows an inversion relative to Salmonella typhimurium LT2. Mol Microbiol 1993, 10(3):655-664

46. Liu SL: Physical mapping of Salmonella genomes. Methods Mol Biol 2007, 394:39-58.

doi:10.1186/1471-2148-10-277

Cite this article as: Chen et al:: Multiple genetic switches spontaneously modulating bacterial mutability. BMC Evolutionary Biology 2010 10:277.

\section{Submit your next manuscript to BioMed Central} and take full advantage of:

- Convenient online submission

- Thorough peer review

- No space constraints or color figure charges

- Immediate publication on acceptance

- Inclusion in PubMed, CAS, Scopus and Google Scholar

- Research which is freely available for redistribution

Submit your manuscript at www.biomedcentral.com/submit 